\title{
First-principles calculations of iron-hydrogen reactions in silicon
}

\author{
Paulo Santos, ${ }^{1, \text { a) }}$ José Coutinho, ${ }^{1}$ and Sven Öberg ${ }^{2}$ \\ 1) Department of Physics and I3N, University of Aveiro, Campus Santiago, 3810-193 Aveiro, \\ Portugal \\ ${ }^{2)}$ Department of Engineering Sciences and Mathematics, Luleå University of Technology, Luleå S-97187, \\ Sweden
}

Controlling the contamination of silicon materials by iron, especially dissolved interstitial iron ( $\left.\mathrm{Fe}_{\mathrm{i}}\right)$, is a longstanding problem with recent developments and several open issues. Among these we have the question whether hydrogen can assist iron diffusion, or if significant amounts of substitutional iron ( $\left.\mathrm{Fe}_{\mathrm{s}}\right)$ can be created. Using density functional calculations we explore the structure, formation energies, binding energies, migration, and electronic levels of several $\mathrm{FeH}$ complexes in $\mathrm{Si}$. We find that a weakly bound $\mathrm{Fe}_{\mathrm{i}} \mathrm{H}$ pair has a migration barrier close to that of isolated $\mathrm{Fe}_{\mathrm{i}}$ and a donor level at $E_{\mathrm{v}}+0.5 \mathrm{eV}$. Conversely, $\mathrm{Fe}_{\mathrm{i}} \mathrm{H}_{2}(0 /+)$ is estimated at $E_{\mathrm{v}}+0.33 \mathrm{eV}$. These findings suggest that the hole trap at $E_{\mathrm{v}}+0.32 \mathrm{eV}$ obtained by capacitance measurements should be assigned to $\mathrm{Fe}_{\mathrm{i}} \mathrm{H}_{2}$. $\mathrm{Fe}_{\mathrm{s}} \mathrm{H}$-related complexes show only deep acceptor activity and are expected to have little effect on minority carrier life-time in $p$-type Si. The opposite conclusion can be drawn for $n$-type $\mathrm{Si}$. We find that while in $\mathrm{H}$-free material $\mathrm{Fe}_{\mathrm{i}}$ defects have lower formation energy than $\mathrm{Fe}_{\mathrm{s}}$, in hydrogenated samples $\mathrm{Fe}_{\mathrm{s}}$-related defects become considerably more stable. This would explain the observation of an EPR signal attributed to a $\mathrm{Fe}_{\mathrm{s}} \mathrm{H}$-related complex in hydrogenated Si, which was quenched from above $1000^{\circ} \mathrm{C}$ to iced-water temperature. Published in Journal of Applied Physics 123, 245703 (2018). https://doi.org/10.1063/1.5039647

\section{INTRODUCTION}

Iron is a fundamental constituent of many tools and industrial equipments, it is present in silicon raw materials, and that makes Fe contamination of Si ingots virtually unavoidable. ${ }^{1,2}$ Stringent control of Fe impurities in $\mathrm{Si}$ is particularly critical in electronic- and solar-grade materials, as a donor level at $E_{\mathrm{v}}+0.38 \mathrm{eV}$ from interstitial iron $\left(\mathrm{Fe}_{\mathrm{i}}\right){ }^{3}$ leads to powerful minority carrier recombination activity in $p$-type $\mathrm{Si}^{4}{ }^{4}$ most often the material of choice for the fabrication of Si solar cells.

Hydrogenation of Silicon wafers has been recurrently applied in order to passivate, or at least reduce, the recombination activity from several defects and contaminants, including iron and other transition metals. ${ }^{2,5-10}$ In Si photovoltaics this hydrogenation process is usually accomplished by means of depositing and firing a hydrogensoaked $\mathrm{SiN}_{x}$ layer on top of $\mathrm{Si}$, which besides the surfacepassivation effect, it also works as an anti-reflection coating for the front surface of the cell. ${ }^{11,12}$ Other types of hydrogen introduction for passivation treatments have also been considered, including proton implantation ${ }^{13}$ or H-plasma exposure, ${ }^{14}$ but none is as convenient as the nitridation process.

The interaction between $\mathrm{Fe}$ and $\mathrm{H}$ in silicon has been addressed in the past. Early studies by Pearton and Tavendale ${ }^{14}$ reported the passivation of iron- and silverrelated centers in $p$-type samples exposed to Hydrogen plasma. Here, the introduction of the metallic impurities was accomplished by high-temperature evaporation, and from deep-level transient spectroscopy (DLTS), the suppression of an electrical level at $E_{\mathrm{v}}+0.32 \mathrm{eV}$, by the time

a) Electronic mail: paulodsantos@ua.pt connected to a Fe-O complex, ${ }^{15}$ after the H-plasma treatment was announced as an interaction between $\mathrm{H}$ and Fe. No direct interaction between $\mathrm{H}$ and interstitial $\mathrm{Fe}$ $\left(\mathrm{Fe}_{\mathrm{i}}\right)$ was reported on these studies. More than a decade later, thermally stimulated capacitance (TSCAP) measurements performed by Sadoh et al. ${ }^{16}$ using iron doped floating-zone $n$-type Si that was subject to wet-etching, displayed the same level, which was then reassigned to a FeH complex. Annealing studies showed that after 30minute treatments at $175^{\circ} \mathrm{C}$, the level disappeared, suggesting a low binding energy between $\mathrm{Fe}$ and $\mathrm{H}$ species. Despite these conclusions, there was no direct evidence for the presence of either $\mathrm{Fe}$ or $\mathrm{H}$ in the ' $E_{\mathrm{v}}+0.32 \mathrm{eV}$ ' center.

More recently, further evidence for a Fe-H complex in $p$-type silicon was reported by Leonard and co-workers. ${ }^{17}$ The hydrogen was introduced into the samples from a silicon nitride layer grown by plasma enhanced chemical vapor deposition. After a reverse-bias annealing at about $100^{\circ} \mathrm{C}$, a hole trap was observed in the DLTS spectrum from samples with high concentrations of Fe and $\mathrm{H}$. This trap was only stable up to $125^{\circ} \mathrm{C}$ and it was related to a donor level at $E_{\mathrm{v}}+0.31 \mathrm{eV}$. The electronic signature of this trap coincided with that reported in Ref. 16.

The interaction of hydrogen with iron-related defects such as the iron-boron $(\mathrm{FeB})$ pair and $\mathrm{Fe}_{\mathrm{i}}$ itself was also addressed by Kouketsu and Isomae. ${ }^{13}$ In this case, hydrogen was introduced by proton implantation, leading different observations when compared to those where hydrogen plasma was used. Accordingly, along with the disappearance of the DLTS signals related to $\mathrm{Fe}_{\mathrm{i}}$ and FeB, the emergence of two hole traps at $E_{\mathrm{v}}+0.23 \mathrm{eV}$ and $E_{\mathrm{v}}+0.38 \mathrm{eV}$ was observed. It was not clear though, whether these new traps arose from the reaction between $\mathrm{H}$ and $\mathrm{Fe}_{\mathrm{i}}$-related complexes, or on the other hand, from complexes involving $\mathrm{H}$ and intrinsic defects (result- 
ing from the implantation damage), eventually combined with Fe.

The interaction of $\mathrm{H}$ with $\mathrm{FeB}$ pairs was also studied by Yakimov and Parakhonsky using wet-etching, ${ }^{18}$ therefore avoiding implantation damage effects. Their results suggested that at room-temperature, the introduction of hydrogen actually leads to dissociation of the FeB pairs in the near surface layer, thus increasing the concentration of interstitial iron. The process leading to such dissociation is not well understood, and therefore it is worth of further investigation.

Electron paramagnetic resonance (EPR) was also employed in the study of H-passivation of Fe in Si. Accordingly, the existence of a $\mathrm{FeH}$ complex with a binding energy of $\sim 1.3 \mathrm{eV}$ and stable up to $<T=220^{\circ} \mathrm{C}$ was inferred after comparing EPR spectra from Fe-doped and (Fe,H)-co-doped $n$-type floating zone $\mathrm{Si}^{19}{ }^{19}$ Interestingly, the EPR signal which was assigned to the $\mathrm{FeH}$ complex was isotropic ( $T_{d}$ symmetry). Unfortunately, the authors could not unambiguously demonstrate the presence of $\mathrm{H}$ atoms in the center, either from the EPR data or from local vibrational mode absorption using deuterated samples.

Theoretical work by the Estreicher group proposed two stable structures for the $\mathrm{FeH}$ complex, namely $\mathrm{Fe}_{\mathrm{i}} \mathrm{H}$ and $\mathrm{Fe}_{\mathrm{s}} \mathrm{H}$, involving interstitial and substitutional $\mathrm{Fe}$, respectively. ${ }^{20}$ Although under equilibrium conditions iron impurities are located at interstitial sites, there is evidence for the existence of substantial concentrations of iron substitutional $\left(\mathrm{Fe}_{\mathrm{S}}\right)$ provided by emission channeling $^{21,22}$ and Mössbauer spectroscopy. ${ }^{23-28}$ The $\mathrm{Fe}_{\mathrm{i}} \mathrm{H}$ model consists on a $\mathrm{Fe}-\mathrm{H}$ dimer with trigonal symmetry, with the Fe atom placed at the hexagonal interstitial site, while $\mathrm{H}$ is located close to a neighboring tetrahedral interstitial site. This structure was anticipated to produce two electrical levels, a donor at $E_{\mathrm{v}}+0.36 \mathrm{eV}$ and an acceptor at $E_{\mathrm{c}}-0.26 \mathrm{eV} .{ }^{20}$ The authors also estimated an energy gain of $0.82 \mathrm{eV}$ for the reaction $\mathrm{Fe}_{\mathrm{i}}+\mathrm{H}_{\mathrm{BC}} \rightarrow \mathrm{Fe}_{\mathrm{i}} \mathrm{H}$ (assuming a bond-centered configuration for hydrogen and neutral defects only), consistent with the thermal stability of the ' $E_{\mathrm{v}}+0.32 \mathrm{eV}$ ' trap (annealing temperature of about $175^{\circ} \mathrm{C}$ ) as reported by Sadoh et al. ${ }^{16}$ This reaction is expected to be hindered in $p$-type $\mathrm{Si}$ due to electrostatic repulsion between $\mathrm{Fe}_{\mathrm{i}}^{+}$ and $\mathrm{H}^{+}$ions.

The second structure, $\mathrm{Fe}_{\mathrm{s}} \mathrm{H}$, was found to comprise an iron atom locked at a substitutional site, with the hydrogen atom roaming almost freely around it. This model was assigned to the EPR spectra reported by Takakashi and co-workers, ${ }^{19}$ conforming to the observed isotropic symmetry. $\mathrm{Fe}_{\mathrm{s}} \mathrm{H}$ was predicted to produce an acceptor level at $E_{\mathrm{c}}-0.62 \mathrm{eV}$. The estimated binding energy for this structure was approximately $1.4 \mathrm{eV}$, also in good agreement with the $1.3 \mathrm{eV}$ binding energy estimated from the ESR measurements ${ }^{19}$. Despite the agreement, the EPR data was acquired in $n$-type material and for these conditions the proposed $\mathrm{Fe}_{\mathrm{s}} \mathrm{H}$ complex would be in a diamagnetic negative charge state, raising doubts to the cor- rectness of this assignment.

While the early literature indicates a relatively low thermal stability for Fe-H complexes (the measured binding energies and annealing experiments on one hand, ${ }^{16,17,19}$ and the first-principles calculations by Szwacki et al. ${ }^{20}$ on the other hand, suggest that these complexes can only survive to temperatures of at most $125-200^{\circ} \mathrm{C}$ ), more recently the solar-Si community has turned the attention to the effect of hydrogenation on Fe diffusivity and gettering at higher temperatures. For instance, Ref. 29 reports a prominent decrease in the concentration of $\mathrm{Fe}_{\mathrm{i}}$ after exposing multicrystalline $\mathrm{Si}$ wafers to a microwave-induced remote hydrogen plasma, followed by $\mathrm{H}$-effusion during $300-500^{\circ} \mathrm{C}$-anneals. This is a surprisingly stable process (when compared to Hpassivation using etched samples), and it was tentatively explained as a consequence of an enhanced diffusion of $\mathrm{Fe}_{\mathrm{i}}$ caused by the introduction of $\mathrm{H}$, thus leading to a faster gettering kinetics.

On the other hand, Liu et al. ${ }^{8}$ questioned the picture of a H-enhanced diffusivity of $\mathrm{Fe}_{i}$, arguing that if that was the case, any increase of the annealing temperatures should lead to the observation of further gettering of Fe. However, they report that at $700^{\circ} \mathrm{C}$, the amount of dissolved iron reaches a minimum of about $1 \%$ of the original content, and recovers at higher temperatures. It was then suggested that up to $700^{\circ} \mathrm{C}$, the formation of a Fe$\mathrm{H}$ complex should account for the decrease of $\mathrm{Fe}_{\mathrm{i}}$, and above that temperature the dissociation of the complex becomes dominant. This view was latter revised after secondary-ion mass spectroscopy (SIMS) measurements combined with DLTS, annealing and analysis of the irondecay kinetics. ${ }^{30}$ From the observed accumulation of Fe at the $\mathrm{SiN}_{x}$ capping layer, it was concluded that the iron reduction in the Si bulk takes place via gettering at the silicon nitride films. Hydrogenation of $\mathrm{Fe}_{\mathrm{i}}$ at hightemperatures was ruled out based on the lack of electrical activity in the Si as monitored by DLTS. Further, upon removal of the $\operatorname{SiN}_{x}$, subsequent high-temperature anneals did not reveal any electrical activity either.

With these observations in mind, we endeavored to calculate the stability, electrical activity and migration ability of FeH-related complexes. After describing the methodology, we report on the atomistic structure and energetics of $\mathrm{FeH}$ defects, their electronic activity, thermal stability and hydrogen-assisted migration of interstitial iron. We end up with a discussion of the results and conclusions.

\section{METHOD}

We employed the Vienna Ab-initio Simulation Package (VASP) code ${ }^{31-33}$ to perform density functional calculations concerning the relative stability, formation energies, electrical levels and migration barriers of $\mathrm{FeH}$ complexes in Si. These calculations were based on the projectoraugmented wave $(\mathrm{PAW})^{34}$ method using the generalized 
gradient approximated exchange-correlation functional of Perdew, Burke and Ernzerhof. ${ }^{35}$ The PAW potentials for $\mathrm{Fe}, \mathrm{Si}$ and $\mathrm{H}$ species were generated in the $3 \mathrm{~s}^{2} 3 \mathrm{p}^{6} 3 \mathrm{~d}^{7} 4 \mathrm{~s}^{1}$, $3 \mathrm{~s}^{2} 3 \mathrm{p}^{2}$ and $1 \mathrm{~s}^{1}$ valence configurations, respectively. The Kohn-Sham states were expanded in plane-waves with a cut off energy of $450 \mathrm{eV}$.

Our atomistic models for the defects under scrutiny were inserted on $216 \mathrm{Si}$ atom supercells with a theoretical lattice parameter of $a_{0}=5.456 \AA$. We employed a $2 \times 2 \times 2$ Monkhorst and Pack k-point grid to sample the Brillouin zone. ${ }^{36}$ The structural optimization of our defect models was done through a conjugate gradient method, with a convergence threshold of $2.5 \times 10^{-3} \mathrm{eV} / \AA$ for the maximum force acting on the nuclei. The self-consistent electronic relaxation cycles were computed with an accuracy of $10^{-7} \mathrm{eV}$.

We employed the marker $\operatorname{method}^{37,38}$ to assess the electrical activity of the $\mathrm{FeH}$ complexes. The markers for the double acceptor, acceptor and donor levels are, respectively: $\mathrm{Ni}_{\mathrm{s}}(=/-)=\mathrm{E}_{\mathrm{c}}-0.08 \mathrm{eV}, \quad \mathrm{Ni}_{\mathrm{s}}(-/ 0)=\mathrm{E}_{\mathrm{c}}-0.31 \mathrm{eV}$ and $\mathrm{Fe}_{\mathrm{i}}(0 /+)=\mathrm{E}_{\mathrm{v}}+0.38 \mathrm{eV} \cdot{ }^{3,39}$ The respective electron affinities $(A)$ and ionization potentials $(I)$ calculated using the same 216-Si supercells are: $A\left\{\mathrm{Ni}_{\mathrm{s}}(=/-)\right\}=6.06 \mathrm{eV}, \quad A\left\{\mathrm{Ni}_{\mathrm{s}}(-/ 0)\right\}=5.99 \mathrm{eV}$ and $I\left\{\mathrm{Fe}_{\mathrm{i}}(0 /+)\right\}=5.73 \mathrm{eV}$. The image-charge corrections for all the markers and defects under scrutiny were accounted for using the algorithm proposed by Freysoldt, Neugebauer and Van de Walle. ${ }^{40}$ The marker method consists on a direct comparison between ionization potentials (or electron affinities) of the marker and that of the defect under scrutiny. While charge-corrections to the energies are of the order of hundreds of $\mathrm{meV}$, these essentially cancel in the calculated electronic levels, becoming a few meV. The error bar of the calculated levels was estimated at about $0.1 \mathrm{eV}$. This figure was estimated by calculating the $\mathrm{Fe}_{\mathrm{i}}$ and $\mathrm{Fe}_{\mathrm{s}}$ levels, but instead of a defect marker, ionization energies and electron affinities of a bulk supercell were assumed as reference energies for the valence band top and conduction band bottom edges, respectively.

Formation energies of neutral defects, $E_{\mathrm{f}}^{0}$, where determined using the following expression:

$$
E_{\mathrm{f}}^{0}=E_{\mathrm{def}}^{0}-\sum_{i} n_{i} \mu_{i}
$$

where $E_{\text {def }}^{0}$ stands for the total energy of a neutral defective supercell made of $n_{i}$ atoms of species $i$ with chemical potential $\mu_{i}$. Chemical potentials $\mu_{\mathrm{Si}}=-5.42 \mathrm{eV}$, $\mu_{\mathrm{Fe}}=-9.68 \mathrm{eV}$ and $\mu_{\mathrm{H}}=-3.39 \mathrm{eV}$ were obtained from bulk $\mathrm{Si}$, iron disilicide $\left(\beta-\mathrm{FeSi}_{2}\right)$ and a $\mathrm{H}_{2}$ molecule in a box, respectively. The formation energy of a defect in charge state $q$ has a $E_{\mathrm{f}}^{q} \sim q E_{\mathrm{F}}$ dependence, where $E_{\mathrm{F}}$ is the Fermi energy with respect to the valence band top. The calculation of $E_{\mathrm{f}}^{q}$ was carried out combining Eq. 1 and the results from the marker method described above. See Ref. 41 for further details.

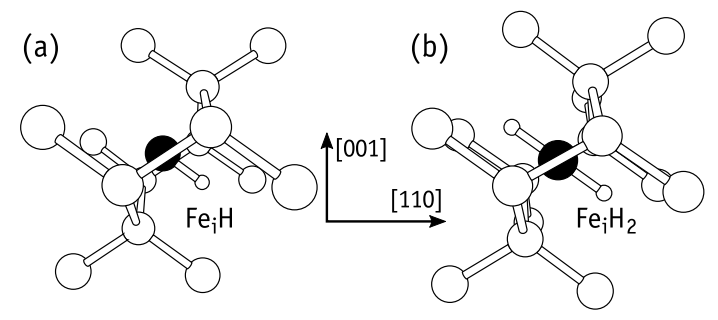

Figure 1. Ground state structure of (a) $\mathrm{Fe}_{\mathrm{i}} \mathrm{H}$ and (b) $\mathrm{Fe}_{\mathrm{i}} \mathrm{H}_{2}$ defects in silicon. The large white, black and small white spheres represent $\mathrm{Si}, \mathrm{Fe}$ and $\mathrm{H}$ atoms, respectively. Fe-H bonds are $1.47 \AA$ long on both defects.

Hydrogen-assisted migration of interstitial iron was also investigated. We employed a 7 -image nudged elastic band (NEB) method ${ }^{42}$ in order to estimate the migration/transformation barriers of FeH-related defects in the neutral and positive charge states. These are the relevant states to be considered in $p$-type material.

\section{RESULTS}

\section{A. Defect Structures}

In order to determine the ground state structures of $\mathrm{Fe}_{\mathrm{i}} \mathrm{H}$ and $\mathrm{Fe}_{\mathrm{s}} \mathrm{H}$ defects, we started from the relaxed structures of $\mathrm{Fe}_{i}$ and $\mathrm{Fe}_{\mathrm{s}}$, respectively, and introduced one or two hydrogen atoms at several possible sites, either bonding directly to the Fe atom along different directions, next to their silicon first neighbors, at second-neighboring SiSi bond-center sites, or near the Fe-Si bond-center site.

In line with the calculations reported by Szwaki et al.,${ }^{20}$ we predict that after trapping one hydrogen atom, the $\mathrm{Fe}_{\mathrm{i}}$ atom becomes more stable near the hexagonal site while connecting to $\mathrm{H}$ along the trigonal axis. The resulting $\mathrm{Fe}_{\mathrm{i}} \mathrm{H}$ structure is depicted in Fig. 1(a). The defect is stable in the negative, neutral and positive charge states with spin $0,1 / 2$ and 1 , respectively. The structure of the $\mathrm{Fe}_{\mathrm{i}} \mathrm{H}_{2}$ complex is analogous, with both $\mathrm{H}$ atoms bonded to $\mathrm{Fe}_{\mathrm{i}}$ pointing towards opposite directions along a common $\langle 111\rangle$ axis. This is shown in Fig. 1(b), and the defect is also stable in the,- 0 , and + charge states with spin $1 / 2,1$ and $1 / 2$, respectively.

In the case of $\mathrm{Fe}_{\mathrm{s}} \mathrm{H}$, we found it to be bistable, with $\mathrm{H}$ connecting to $\mathrm{Fe}_{\mathrm{s}}$ along the $\langle 100\rangle$ direction in the neutral charge state, or along $\langle 111\rangle$ towards the tetrahedral interstitial site in the negative charge state. These structures are represented in the configuration coordinate diagram of Fig. 2, and are labeled as $\left\{\mathrm{Fe}_{\mathrm{S}} \mathrm{H}\right\}_{\mathrm{A}}^{0}$ and $\left\{\mathrm{Fe}_{\mathrm{S}} \mathrm{H}\right\}_{\mathrm{B}}^{-}$respectively. They show spin $1 / 2$ and 0 , respectively, and each of them has a unique minimum in the potential energy surface: for the negatively charged defect, structural optimization initiated in the $\left\{\mathrm{Fe}_{\mathrm{S}} \mathrm{H}\right\}_{\mathrm{A}}$ configuration relaxed into $\left\{\mathrm{Fe}_{\mathrm{S}} \mathrm{H}\right\}_{\mathrm{B}}$. Conversely, neutral $\left\{\mathrm{Fe}_{\mathrm{S}} \mathrm{H}\right\}_{\mathrm{B}}$ is unstable and spontaneously relaxes to $\left\{\mathrm{Fe}_{\mathrm{S}} \mathrm{H}\right\}_{\mathrm{A}}^{0}$. The energy barriers for conversion between $\left\{\mathrm{Fe}_{\mathrm{S}} \mathrm{H}\right\}_{\mathrm{A}} \leftrightarrow\left\{\mathrm{Fe}_{\mathrm{S}} \mathrm{H}\right\}_{\mathrm{B}}$ were 
calculated as $0.26 \mathrm{eV}$ and $0.32 \mathrm{eV}$ for neutral and negative charged defects. These figures are at variance with those obtained in Ref. $20(0.08 \mathrm{eV})$ and we can only suggest that in that work the Brillouin-zone sampling that was employed ( $\Gamma$-only) was not sufficiently dense considering the size of the supercells (64 atoms).

The capture of a second hydrogen atom by $\mathrm{Fe}_{\mathrm{s}}$ also leads to two stable $\mathrm{Fe}_{\mathrm{s}} \mathrm{H}_{2}$ configurations in different charge states. For the neutral charge state we obtained a linear $\mathrm{H}-\mathrm{Fe}-\mathrm{H}$ configuration with both $\mathrm{Fe}-\mathrm{H}$ bonds along the $\langle 100\rangle$ crystallographic axis, pointing towards opposite directions. This structure has high symmetry $\left(D_{2 d}\right.$ point group) and from inspection of the Kohn-Sham band structure with identified an empty double degenerate state in the upper half of the gap. We label this structure $\left\{\mathrm{Fe}_{\mathrm{S}} \mathrm{H}_{2}\right\}_{\mathrm{A}}$.

In the negative charge state the doublet state becomes partially populated and the structure undergoes a JahnTeller distortion. This translates into a $E_{\mathrm{JT}} \sim 0.3 \mathrm{eV}$ relaxation energy and to the formation of a slanted $\mathrm{Fe}-\mathrm{H}$ bond about $10^{\circ}$ away from the $\langle 100\rangle$ axis. Several other low-energy distortions were found within $30 \mathrm{meV}$ from the ground state. These consisted of pairs of $\mathrm{Fe}-\mathrm{H}$ bonds oriented close to $\langle 100\rangle$ and $\langle 111\rangle$, like in $\left\{\mathrm{Fe}_{\mathrm{S}} \mathrm{H}\right\}_{\mathrm{A}}$ and $\left\{\mathrm{Fe}_{\mathrm{S}} \mathrm{H}\right\}_{\mathrm{B}}$, respectively. All non-linear $\mathrm{H}-\mathrm{Fe}-\mathrm{H}$ defects (including the ground state) were found with spin $1 / 2$, and because they are all nearly degenerate, we refer to them as $\left\{\mathrm{Fe}_{\mathrm{S}} \mathrm{H}_{2}\right\}_{\mathrm{B}}$. Interestingly, the transformation barrier between these low-symmetry structures was found to be about $50 \mathrm{meV}$, indicating that the $\mathrm{H}$ atoms can roam almost freely around the $\mathrm{Fe}_{\mathrm{s}}$ impurity, even at cryogenic temperatures.

In the double negative charge state, the Jahn-Teller distortion becomes stronger and both $\mathrm{Fe}_{\mathrm{s}}-\mathrm{H}$ bonds pointed approximately along orthogonal $\langle 100\rangle$ directions. The resulting diamagnetic $\left\{\mathrm{Fe}_{\mathrm{S}} \mathrm{H}_{2}\right\}_{\mathrm{B}}$ state was found more stable than the paramagnetic $\left\{\mathrm{Fe}_{\mathrm{S}} \mathrm{H}_{2}\right\}_{\mathrm{A}}=$ linear structure with spin- 1 by $0.29 \mathrm{eV}$. The reorientation of a $\mathrm{Fe}_{\mathrm{s}}-\mathrm{H}$ bond now involves surmounting a barrier of $0.12 \mathrm{eV}$. All Fe-H bond lengths in $\mathrm{Fe}_{\mathrm{s}} \mathrm{H}_{n}$ defects were in the range of $1.52-1.55 \AA$.

Besides the electronic energy (enthalpy), at high temperatures the entropy may impact on the relative stability of defects, and here the most important contributions are from configurational and vibrational degrees of freedom. Sanati and Estreicher found that vibrational entropy can stabilize light impurities in silicon by $\sim 0.1-0.2 \mathrm{eV}$ after ramping up the temperature by up to $\Delta T=800 \mathrm{~K}^{43}$ Assuming that the magnitude of Fe-H vibrational frequencies from $\left\{\mathrm{Fe}_{\mathrm{S}} \mathrm{H}\right\}_{\mathrm{A}}$ and $\left\{\mathrm{Fe}_{\mathrm{S}} \mathrm{H}\right\}_{\mathrm{B}}$ are not very different, the vibrational entropy difference is expected to be minute. Configurational entropy is normally not considered because it is difficult to estimate analytically except for very simple structures. ${ }^{44}$ Within the Boltzmann framework, the configurational entropy difference between structures $\left\{\mathrm{Fe}_{\mathrm{S}} \mathrm{H}\right\}_{\mathrm{A}}$ and $\left\{\mathrm{Fe}_{\mathrm{S}} \mathrm{H}\right\}_{\mathrm{B}}$ is about $k_{\mathrm{B}} \ln (6 / 4) \approx 3.5 \times 10^{-5} \mathrm{eV} / \mathrm{K}$, which translates into a mere $27 \mathrm{meV}$ for $\Delta T=800 \mathrm{~K}$. Although a de-

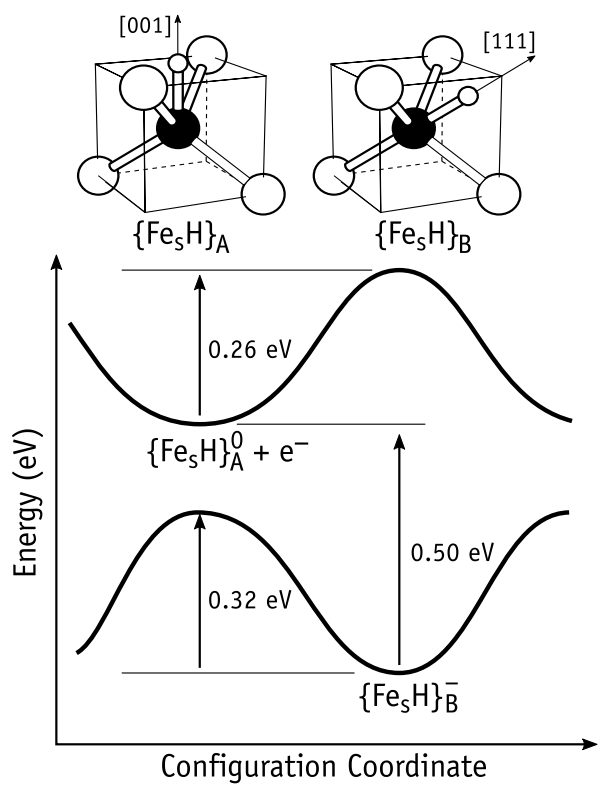

Figure 2. Configuration coordinate diagram of the $\mathrm{Fe}_{\mathrm{S}} \mathrm{H}$ defect. The upper part of the figure includes the two groundstate configurations $\left\{\mathrm{Fe}_{\mathrm{S}} \mathrm{H}\right\}_{\mathrm{A}}$ and $\left\{\mathrm{Fe}_{\mathrm{S}} \mathrm{H}\right\}_{\mathrm{B}}$ for neutral and negative charge states, respectively. The black sphere represents Fe while the smaller and larger white spheres represent $\mathrm{H}$ and $\mathrm{Si}$, respectively.

tailed account of entropy effects is outside the scope of this work, the picture just presented should not be generalized, and we should bear in mind that entropy could have a stronger influence, particularly when comparing energies of defects with different stoichiometry and lattice locations.

\section{B. Electronic levels}

The donor level of interstitial iron in silicon has been experimentally determined at $E_{\mathrm{v}}+0.38 \mathrm{eV} .{ }^{3}$ We investigated the reaction of $\mathrm{H}$ with $\mathrm{Fe}_{i}$ in terms of the resulting electronic activity. Since $\mathrm{Fe}_{\mathrm{i}}$ is displaced from the tetrahedral site to the hexagonal site upon bonding with one or two $\mathrm{H}$ atoms, the electronic activity of $\mathrm{Fe}_{\mathrm{i}} \mathrm{H}$ complexes is expected to differ significantly from that of isolated $\mathrm{Fe}_{\mathrm{i}}$. In fact, we found that besides donor activity, both $\mathrm{Fe}_{\mathrm{i}} \mathrm{H}$ and $\mathrm{Fe}_{\mathrm{i}} \mathrm{H}_{2}$ complexes are acceptors. For the $\mathrm{Fe}_{\mathrm{i}} \mathrm{H}$ pair we obtain $(-/ 0)$ and $(0 /+)$ levels at $E_{\mathrm{c}}-0.22 \mathrm{eV}$ and $E_{\mathrm{v}}+0.50 \mathrm{eV}$. On the other hand, for $\mathrm{Fe}_{\mathrm{i}} \mathrm{H}_{2}$ we calculated $(-/ 0)$ and $(0 /+)$ levels at $E_{\mathrm{c}}-0.29 \mathrm{eV}$ and $E_{\mathrm{v}}+0.33 \mathrm{eV}$, respectively. No further levels were found for $\mathrm{Fe}_{\mathrm{i}} \mathrm{H}_{n}$ defects. Although our results for $\mathrm{Fe}_{\mathrm{i}} \mathrm{H}$ are not far from previous theoretical reports, ${ }^{20}$ the $\mathrm{Fe}_{\mathrm{i}} \mathrm{H}(0 /+)$ level seems too deep to be connected to the ' $E_{\mathrm{v}}+0.32 \mathrm{eV}^{\prime}$ trap of Ref. 16. Alternatively, $\mathrm{Fe}_{\mathrm{i}} \mathrm{H}_{2}$ shows a $(0 /+)$ transition at $E_{\mathrm{v}}+0.33 \mathrm{eV}$, i.e. about the right placement within the gap, and therefore, must be considered as potentially accountable for the above trap as well. We will come back 
Table I. Calculated electrical levels for $\mathrm{Fe}_{\mathrm{i}} \mathrm{H}_{\mathrm{n}}$ and $\mathrm{Fe}_{\mathrm{S}} \mathrm{H}_{\mathrm{n}}$ complexes. All reported values are in $\mathrm{eV}$. The inverted order of levels for $\mathrm{Fe}_{\mathrm{S}} \mathrm{H}_{2}$ leads to a $(=/ 0)$ occupancy level at $E_{\mathrm{c}}-0.26 \mathrm{eV}$ (see text).

\begin{tabular}{cccc}
\hline \hline & $E_{\mathrm{c}}-E(=/-)$ & $E_{\mathrm{c}}-E(-/ 0)$ & $E(0 /+)-E_{\mathrm{v}}$ \\
\hline $\mathrm{Fe}_{\mathrm{i}} \mathrm{H}$ & & 0.22 & 0.50 \\
$\mathrm{Fe}_{\mathrm{i}} \mathrm{H}_{2}$ & & 0.29 & 0.33 \\
$\mathrm{Fe}_{\mathrm{S}} \mathrm{H}$ & & 0.50 & \\
$\mathrm{Fe}_{\mathrm{s}} \mathrm{H}_{2}$ & 0.30 & 0.21 & \\
\hline \hline
\end{tabular}

to this issue in Section III D.

Now we turn to the interactions between $\mathrm{H}$ and substitutional iron. For $\left\{\mathrm{Fe}_{\mathrm{S}} \mathrm{H}\right\}_{\mathrm{A}}$ and $\left\{\mathrm{Fe}_{\mathrm{S}} \mathrm{H}\right\}_{\mathrm{B}}$ we obtained vertical $(-/ 0)$ transitions at $\mathrm{E}_{\mathrm{c}}-0.18 \mathrm{eV}$ and $\mathrm{E}_{\mathrm{c}}-0.76 \mathrm{eV}$. However, we note that $\left\{\mathrm{Fe}_{\mathrm{S}} \mathrm{H}\right\}_{\mathrm{A}}^{-}$and $\left\{\mathrm{Fe}_{\mathrm{S}} \mathrm{H}\right\}_{\mathrm{B}}^{0}$ are unstable, and the relevant thermodynamic acceptor level of $\mathrm{Fe}_{\mathrm{S}} \mathrm{H}$ must be calculated from ground state energies. Hence, we obtain $\mathrm{Fe}_{\mathrm{s}} \mathrm{H}(-/ 0)$ at $E_{\mathrm{c}}-0.50 \mathrm{eV}$ (see Fig. 2). Previous first-principles calculation ${ }^{20}$ assigned $\mathrm{Fe}_{\mathrm{S}} \mathrm{H}$ in the neutral charge state to an isotropic spin- $1 / 2$ EPR spectrum observed in $n$-type material at a temperature as low as $10 \mathrm{~K}^{19}{ }^{19}$ The location of the $\mathrm{Fe}_{\mathrm{s}} \mathrm{H}(-/ 0)$ level implies that under these conditions, the defect would be found in a diamagnetic negative charge state, and therefore undetectable by EPR. We could not find a second acceptor level for $\mathrm{Fe}_{\mathrm{S}} \mathrm{H}$. Hence, the assignment of the EPR data should be revised and further work is needed to clarify this point.

For $\mathrm{Fe}_{\mathrm{S}} \mathrm{H}_{2}$ we anticipate first and second acceptor levels at $\mathrm{E}_{\mathrm{c}}-0.21 \mathrm{eV}$ and $\mathrm{E}_{\mathrm{c}}-0.30 \mathrm{eV}$, respectively. It is noteworthy that the second electron trap is deeper than the first, i.e. $\mathrm{Fe}_{\mathrm{s}} \mathrm{H}_{2}$ shows an inverted ordering of the acceptor levels. This is commonly referred to as negative- $U$ and arrises from a strong relaxation energy along the capture sequence, which surmounts the Coulomb repulsion between both captured electrons. Accordingly, in the neutral charge state $\mathrm{Fe}_{\mathrm{S}} \mathrm{H}_{2}$ adopts structure A. This structure can capture a free-electron with a binding energy of $0.21 \mathrm{eV}$. After trapping the first electron, the structure quickly changes to $\left\{\mathrm{Fe}_{\mathrm{S}} \mathrm{H}_{2}\right\}_{\mathrm{B}}$, where some of the relaxation energy is effectively converted to an increase of the Coulomb attraction for the second electron, leading to a binding energy of $0.30 \mathrm{eV}$. The consequence of the negative- $U$ ordering of levels is that, under equilibrium conditions, it is energetically favorable to form a pair of $\left\{\mathrm{Fe}_{\mathrm{s}} \mathrm{H}_{2}\right\}^{0}$ and $\left\{\mathrm{Fe}_{\mathrm{s}} \mathrm{H}_{2}\right\}^{=}$states than two $\left\{\mathrm{Fe}_{\mathrm{S}} \mathrm{H}_{2}\right\}^{-}$structures (irrespectively of the Fermi level position). Hence, $\mathrm{Fe}_{\mathrm{S}} \mathrm{H}_{2}$ has an $(=/ 0)$ occupancy level that is located halfway between the first and second acceptor levels, i.e. $\mathrm{Fe}_{\mathrm{S}} \mathrm{H}_{2}(=/ 0)=E_{\mathrm{c}}-0.26 \mathrm{eV}$. All calculated electrical levels are shown in Table I.

\section{Binding energies and doping effects}

The diagrams presented in Figure 3 show formation energies of several defect sets involving one $\mathrm{Fe}_{\mathrm{i}}$ impurity plus two interstitial $\mathrm{H}$ atoms (left), in comparison with one $\mathrm{Fe}_{\mathrm{s}}$ impurity plus two interstitial $\mathrm{H}$ atoms (right) as a function of the Fermi energy. On each diagram the stoichiometry is conserved. The formation energy (vertical) scales are identical for a convenient comparison. Each sequence of connected segments relates to a particular set involving a $\mathrm{Fe}_{\mathrm{i}} \mathrm{H}_{n}$ or $\mathrm{Fe}_{\mathrm{S}} \mathrm{H}_{n}$ complex plus $2-n$ remote interstitial $\mathrm{H}$ atoms. The formation energy is proportional to $q E_{\mathrm{F}}$, with $q$ and $E_{\mathrm{F}}$ being the net charge of the whole defect set and Fermi level, respectively. Hence, positive-, zero- and negative-sloped segments refer to defect sets with net positive, neutral and negative charge, respectively. For instance, for $\mathrm{Fe}_{\mathrm{i}} \mathrm{H}$ plus a remote $\mathrm{H}$ atom (on the left diagram), as the Fermi energy goes from the valence band top $\left(E_{\mathrm{F}}=0\right)$ to the conduction band bottom $\left(E_{\mathrm{F}}=1.17 \mathrm{eV}\right)$, the sequence is: $\left\{\mathrm{Fe}_{\mathrm{i}} \mathrm{H}\right\}^{+}+\mathrm{H}_{\mathrm{BC}}^{+}$(net charge $\left.q=+2\right) ;\left\{\mathrm{Fe}_{\mathrm{i}} \mathrm{H}\right\}^{0}+\mathrm{H}_{\mathrm{BC}}^{+}$ (net charge $q=+1) ;\left\{\mathrm{Fe}_{\mathrm{i}} \mathrm{H}\right\}^{0}+\mathrm{H}_{\mathrm{T}}^{-}$(net charge $q=-1$ ); $\left\{\mathrm{Fe}_{\mathrm{i}} \mathrm{H}\right\}^{-}+\mathrm{H}_{\mathrm{T}}^{-}$(net charge $q=-2$ ). Hence, each kink between adjacent segments corresponds to a particular transition level identified in the Figure. We note that transition levels of $\mathrm{Fe}_{\mathrm{i}}$ and interstitial $\mathrm{H}$ are measured. The latter is a negative- $U$ defect with donor and acceptor levels at $E_{\mathrm{c}}-0.18 \mathrm{eV}$ and $E_{\mathrm{c}}-0.5 \mathrm{eV}$, leading to a $(-/+)$ occupancy level at $E_{\mathrm{c}}-0.34 \mathrm{eV} \cdot{ }^{45-48}$ Positive and negatively charged $\mathrm{H}$ defects are more stable at the bondcenter $\left(\mathrm{H}_{\mathrm{BC}}^{+}\right)$and tetrahedral interstitial sites $\left(\mathrm{H}_{\mathrm{BC}}^{-}\right)$, respectively. The neutral charge state (used to calculate the formation energy in Eq. 1) was found more stable in the bond-center site $\left(\mathrm{H}_{\mathrm{BC}}^{0}\right)$. Experimental and calculated levels are highlighted by open and closed circles on both diagrams. Finally, on the diagram related to $\mathrm{Fe}_{\mathrm{s}} \mathrm{H}_{n}$ defects, we made use of color to distinguish $\mathrm{A}$ and $\mathrm{B}$ structures of $\mathrm{Fe}_{\mathrm{s}} \mathrm{H}$ and $\mathrm{Fe}_{\mathrm{s}} \mathrm{H}_{2}$ complexes.

Looking at the diagram on the left-hand side of Figure 3 we conclude that the capture of atomic $\mathrm{H}$ by $\mathrm{Fe}_{\mathrm{i}}$ is an energetically favorable process regardless of the Fermi level position. The energy drop of the formation energy as we move from the upper segments $\left(\mathrm{Fe}_{\mathrm{i}}+2 \mathrm{H}\right)$ down to the lower segments $\left(\mathrm{Fe}_{\mathrm{i}} \mathrm{H}_{2}\right)$, represents the binding energy of the reaction $\mathrm{H}+\mathrm{Fe}_{\mathrm{i}} \mathrm{H}_{n} \rightarrow \mathrm{Fe}_{\mathrm{i}} \mathrm{H}_{n+1}$, with $n=0$ or 1. In intrinsic material (considering the Fermi level to be approximately at mid-gap), the capture of $\mathrm{H}$ by $\mathrm{Fe}_{\mathrm{i}}$ corresponds to an energy gain of $\sim 0.56 \mathrm{eV}$. The capture of a second hydrogen atom corresponds to an energy gain of $\sim 0.80 \mathrm{eV} \mathrm{eV}$, leading to a total binding energy of $\sim 1.36 \mathrm{eV}$ to form a neutral $\mathrm{Fe}_{\mathrm{i}} \mathrm{H}_{2}$ complex. In $p$-type materials these reactions become less exothermic and the formation of $\mathrm{Fe}_{\mathrm{i}} \mathrm{H}_{n}$ complexes becomes less likely. Hydrogenation of $\mathrm{Fe}_{\mathrm{i}}$ is further hindered in $p$-type Si due to the fact that both $\mathrm{H}$ and $\mathrm{Fe}_{\mathrm{i}} \mathrm{H}_{n}$ complexes are deep donors, implying a long-range Coulomb repulsion between reactants. On the other hand, in $n$-type Si there is no Coulomb barrier for the reaction $\mathrm{Fe}_{\mathrm{i}}^{0}+\mathrm{H}_{\mathrm{T}}^{-} \rightarrow \mathrm{Fe}_{\mathrm{i}} \mathrm{H}^{-}$ 


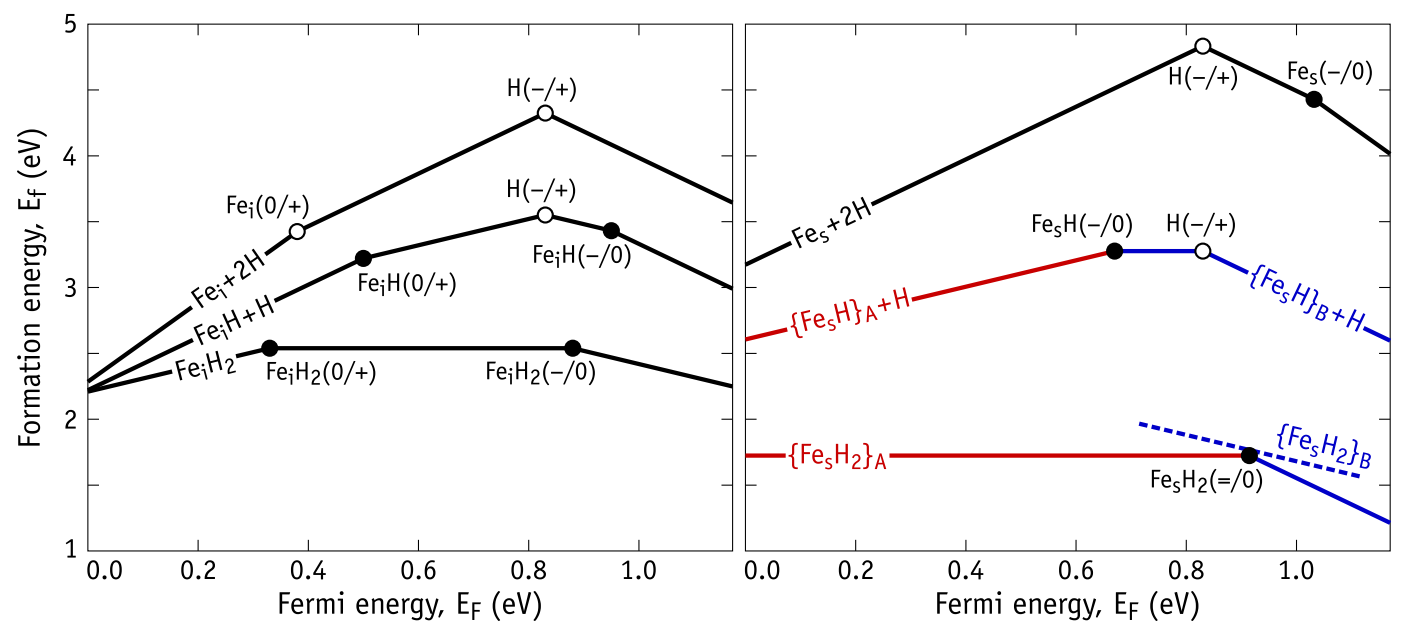

Figure 3. Diagrams with the formation energy $\left(E_{\mathrm{f}}\right)$ as a function of the Fermi energy $\left(E_{\mathrm{F}}\right)$ for different defect arrangements involving the hydrogenation of $\mathrm{Fe}_{\mathrm{i}}$ (left) and $\mathrm{Fe}_{\mathrm{s}}$ (right) defects. Open and closed circles highlight experimental and calculated electronic levels. Colors on the right diagram are used to clarify A (red) and B (blue) structures of $\mathrm{Fe}_{\mathrm{s}} \mathrm{H}$ and $\mathrm{Fe}_{\mathrm{s}} \mathrm{H}_{2}$ complexes. See text at the beginning of Section III C for further details.

and the energy drop is $\sim 0.6 \mathrm{eV}$. The reaction with a second hydrogen atom has a binding energy of $0.75 \mathrm{eV}$, but it is likely to be inhibited by repulsion between $\mathrm{H}_{\mathrm{T}}^{-}$and $\left\{\mathrm{Fe}_{\mathrm{S}} \mathrm{H}\right\}^{-}$. In summary, hydrogenation of interstitial iron in $\mathrm{Si}$ leads to $\mathrm{Fe}_{\mathrm{i}} \mathrm{H}_{n}$ complexes whose binding energies are low, and they are compatible with the the annealing temperature of $125-175^{\circ} \mathrm{C}$ of the FeH-related complex reported in Refs. 16 and 17.

The diagram on the right-hand side of Figure 3 immediately suggests that $\mathrm{H}$ binds strongly to $\mathrm{Fe}_{\mathrm{s}}$, regardless of the doping type. In n-type $\mathrm{Si}$ the binding energies are $\sim 1.4 \mathrm{eV}$, in excellent agreement with the measured binding energy of $1.3 \mathrm{eV}$ for a FeH-related complex in $n$-type $\mathrm{Si}$, where Fe was suggested to be at the substitutional site. ${ }^{19}$ In the lower part of the right diagram we also represent the formation energy of the negatively charged $\left\{\mathrm{Fe}_{\mathrm{s}} \mathrm{H}_{2}\right\}_{\mathrm{B}}^{-}$, just above the $\mathrm{Fe}_{\mathrm{s}} \mathrm{H}_{2}(=/ 0)$ negative$U$ transition at $E_{\mathrm{c}}-0.26 \mathrm{eV}$. This is show as a dashed line to stress its metastable character.

A more judicious inspection of Figure 3 allows us to conclude that, while in hydrogen-free material iron impurities have a lower formation energy at the interstitial site, in $\mathrm{H}$-doped $\mathrm{Si}$, the lower formation energy complexes are those involving substitutional iron. This suggests that even in $p$-type $\mathrm{Si}$, high temperature anneals (maybe with optical excitation in order to avoid Coulomb repulsion by changing the charge state of either $\mathrm{H}$ or $\mathrm{Fe}$ impurities), may be able to convert highly mobile and recombination active $\mathrm{Fe}_{\mathrm{i}}$ impurities into stable and lowrecombination active $\mathrm{Fe}_{\mathrm{s}}$ impurities, where $\mathrm{H}$ atoms act as catalysts. Although we are not the first to realize this possibility ${ }^{20}$ it lacked theoretical support and it has been overlooked by the solar-Si community.

\section{H-assisted diffusivity of iron}

Bearing in mind the observation of the enhancement of Fe-gettering upon introduction of hydrogen (see for instance Refs. 8, 29, and 30), and considering the high thermal stability of the species (or phase) holding the $\mathrm{Fe}$ (which survives to temperatures above $500^{\circ} \mathrm{C}$ ), we investigated an eventual enhanced migration of $\mathrm{Fe}_{i}$ assisted by $\mathrm{H}$. This could lead to a faster formation of iron precipitates or out-diffusion from the Si. For the $\mathrm{Fe}_{\mathrm{i}}$ we considered a simple interstitial mechanism through the hexagonal site. In the case $\mathrm{Fe}_{\mathrm{i}} \mathrm{H}$, the defect was found to travel as a molecule, also through neighboring hexagonal sites. As we mentioned before, a total of $7 \mathrm{NEB}$ images were considered in order to determine the saddle point along the minimum energy path. The calculated migration barriers are $0.50 \mathrm{eV}, 0.65 \mathrm{eV}$ and $0.61 \mathrm{eV}$ for $\mathrm{Fe}_{\mathrm{i}}^{+},\left\{\mathrm{Fe}_{\mathrm{i}} \mathrm{H}\right\}^{0}$ and $\left\{\mathrm{Fe}_{\mathrm{i}} \mathrm{H}\right\}^{+}$respectively. The barrier for migration of $\mathrm{Fe}_{\mathrm{i}}^{+}$is in very good agreement with the measurements, which is about $0.6 \mathrm{eV}$ (see Ref. 4 and references therein). Both $\left\{\mathrm{Fe}_{\mathrm{i}} \mathrm{H}\right\}^{0}$ and $\left\{\mathrm{Fe}_{\mathrm{i}} \mathrm{H}\right\}^{+}$have migration barriers comparable to that of interstitial iron, and in p-type Si they are considerably larger than the binding energy of $\mathrm{H}$ to $\mathrm{Fe}_{\mathrm{i}}$. These results suggest that hydrogen, if able to attach to $\mathrm{Fe}_{\mathrm{i}}$, does not enhance its diffusivity.

\section{DISCUSSION AND CONCLUSIONS}

We calculated the structure, formation energies, binding energies, and electronic levels of several $\mathrm{FeH}$ complexes in $\mathrm{Si} . \mathrm{Fe}_{\mathrm{i}} \mathrm{H}$ and $\mathrm{Fe}_{\mathrm{i}} \mathrm{H}_{2}$ defects consist on $\mathrm{Fe}-\mathrm{H}$ and $\mathrm{H}-\mathrm{Fe}-\mathrm{H}$ pseudo-molecules, respectively, with the $\mathrm{Fe}$ and $\mathrm{H}$ atoms being located close to hexagonal and tetrahedral interstitial sites of the lattice. The modest bind- 
ing energies of the $\mathrm{H}$ atoms to $\mathrm{Fe}_{\mathrm{i}}$ seem consistent with the annealing temperature in the range of $125-175^{\circ} \mathrm{C}$ reported for a hole trap at $E_{\mathrm{v}}+0.32 \mathrm{eV}$ and assigned to an iron-hydrogen complex. ${ }^{16,17,20}$ However, an assignment to $\mathrm{Fe}_{\mathrm{i}} \mathrm{H}$ (with a single $\mathrm{H}$ atom) conflicts with its predicted migration barrier, which is close to that of $\mathrm{Fe}_{\mathrm{i}}$. Accordingly, both defects are expected to anneal out at close temperatures (just above room temperature). For the same reasons, $\mathrm{Fe}_{\mathrm{i}} \mathrm{H}$ complexes are not able to account for the reduction of $\mathrm{Fe}_{\mathrm{i}}$ upon annealing hydrogenated multicrystalline wafers in the temperature range of 700 $900^{\circ} \mathrm{C} .^{8,29,30}$

$\mathrm{Fe}_{\mathrm{i}} \mathrm{H}$ and $\mathrm{Fe}_{\mathrm{i}} \mathrm{H}_{2}$ complexes were predicted to be simultaneously deep donors and acceptors, and therefore are not expected to substantially decrease the recombination activity of $\mathrm{Fe}$ in $\mathrm{Si}$. The calculated levels and binding energies suggest that the donor level measured at $E_{\mathrm{v}}+0.32 \mathrm{eV}$ from Refs. 16 and 17 is likely to arise from a $\mathrm{Fe}_{\mathrm{i}} \mathrm{H}_{n}$ complex involving 2 or more $\mathrm{H}$ atoms. The $\mathrm{Fe}_{\mathrm{i}} \mathrm{H}_{2}(0 /+)$ transition is predicted at $E_{\mathrm{v}}+0.33 \mathrm{eV}$, while $\mathrm{Fe}_{\mathrm{i}} \mathrm{H}(0 /+)$ is anticipated to occur close to mid-gap.

Substitutional iron and $\mathrm{Fe}_{\mathrm{s}} \mathrm{H}_{n}$ complexes are acceptors. No donor levels were found for these defects. For the $\mathrm{Fe}_{\mathrm{S}} \mathrm{H}$ pair we obtain a single acceptor level close to mid-gap. While this result is in line with Ref. 20, it is not regarding the calculated barrier for $\mathrm{H}$ motion around the $\mathrm{Fe}_{\mathrm{s}}$ impurity. In that work, the barrier was estimated to be as low as $0.08 \mathrm{eV}$, allowing the assignment of neutral $\mathrm{Fe}_{\mathrm{S}} \mathrm{H}$ to an isotropic EPR center observed in $n$-type Si. ${ }^{19}$ Our results do not corroborate this view. The calculated barrier for $\mathrm{Fe}-\mathrm{H}$ bond reorientation is anticipated to be as high as $0.26 \mathrm{eV}$, which is not compatible with a fast-orbiting $\mathrm{H}$ atom and a motional-averaged tetrahedral symmetry at $T=10 \mathrm{~K}$. Further, the near mid-gap location of the calculated $\mathrm{Fe}_{\mathrm{S}} \mathrm{H}(-/ 0)$ deep acceptor means that in $n$-type material the stable state is diamagnetic $\mathrm{Fe}_{\mathrm{S}} \mathrm{H}^{-}$(undetectable by EPR).

Regarding $\mathrm{Fe}_{\mathrm{S}} \mathrm{H}_{2}$, we found a $\langle 100\rangle$-aligned $\mathrm{H}-\mathrm{Fe}-\mathrm{H}$ linear structure in the neutral charge state. The point symmetry of the defect is $D_{2 d}$ and it has an empty doublet in the gap. Negative and double negative charge states are sensitive to Jahn-Teller distortions. The negatively charged defect is particularly interesting as it shows several possible low energy configurations with different angles between Fe-H bonds, differing by at most $30 \mathrm{meV}$ in their relative energy and separated by reorientation barriers as shallow as $50 \mathrm{meV}$. Based on these findings, we suggest that the FeH-related EPR signal from Ref. 19 arises from $\mathrm{Fe}_{\mathrm{S}} \mathrm{H}_{2}^{-}$or other $\mathrm{Fe}_{\mathrm{s}} \mathrm{H}_{n}$ complex with $n>2$. The later option is perhaps the most probable as $\mathrm{Fe}_{\mathrm{S}} \mathrm{H}_{2}$ is a negative- $U$ complex with a metastable negative state (see dashed line segment on the right diagram of Figure 3).

Figure 3 shows that the formation energy of $\mathrm{Fe}_{\mathrm{i}}$ in nonhydrogenated $\mathrm{Si}$ is lower than that of $\mathrm{Fe}_{\mathrm{S}}$ by about $0.5 \mathrm{eV}$. This explains the preference of iron to occupy interstitial sites. However, in the presence of hydrogen the formation of $\mathrm{Fe}_{\mathrm{s}}$-related complexes becomes favorable. This could explain the formation of large amounts of $\mathrm{Fe}_{\mathrm{S}} \mathrm{H}$ related defects in hydrogenated $\mathrm{Si}$, as detected by EPR after quenching the samples from $950-1250^{\circ} \mathrm{C}$ to $0^{\circ} \mathrm{C} \cdot{ }^{19}$

\section{ACKNOWLEDGEMENTS}

This work was funded by the Fundação para a Ciência e a Tecnologia (FCT) under projects PTDC/CTM$\mathrm{ENE} / 1973 / 2012$ and UID/CTM/50025/2013, and funded by FEDER funds through the COMPETE 2020 Program. Computer resources were provided by the Swedish National Infrastructure for Computing (SNIC) at PDC.

\section{REFERENCES}

${ }^{1}$ L. Jastrzebski, J.Lagowski, W. Henley, and P. Edelman, MRS Proceedings 354, 405 (1994).

${ }^{2}$ A. A. Istratov, H. Hieslmair, and E. R. Weber, Applied Physics A 70, 489 (2000).

${ }^{3}$ H. Feichtinger, J. Waltl, and A. Gschwandtner, Solid State Communications 27, 867 (1978).

${ }^{4}$ A. A. Istratov, H. Hieslmair, and E. R. Weber, Applied Physics A 69, 13 (1999).

${ }^{5}$ S. J. Pearton and A. J. Tavendale, Physical Review B 26, 7105 (1982).

${ }^{6}$ R. Singh, S. J. Fonash, and A. Rohatgi, Applied Physics Letters 49, 800 (1986).

${ }^{7}$ A. R. Peaker, V. P. Markevich, B. Hamilton, G. Parada, A. Dudas, A. Pap, E. Don, B. Lim, J. Schmidt, L. Yu, Y. Yoon, and G. Rozgonyi, physica status solidi (a) 209, 1884 (2012).

${ }^{8}$ A. Liu, C. Sun, and D. Macdonald, Journal of Applied Physics 116, 194902 (2014).

${ }^{9}$ L. Scheffler, V. Kolkovsky, and J. Weber, Journal of Applied Physics 117, 085707 (2015).

${ }^{10}$ J. Mullins, S. Leonard, V. P. Markevich, I. D. Hawkins, P. Santos, J. Coutinho, A. G. Marinopoulos, J. D. Murphy, M. P. Halsall, and A. R. Peaker, physica status solidi (a) 214, 1700304 (2017), 1700304 .

${ }^{11}$ F. Jiang, M. Stavola, A. Rohatgi, D. Kim, J. Holt, H. Atwater, and J. Kalejs, Applied Physics Letters 83, 931 (2003).

12 J. K. Holt, D. G. Goodwin, A. M. Gabor, F. Jiang, M. Stavola, and H. A. Atwater, Thin Solid Films 430, 37 (2003), proceedings of the Second International Conference on Cat-CVD (Hot Wire CVD) Process.

${ }^{13} \mathrm{M}$. Kouketsu and S. Isomae, Journal of Applied Physics 80, 1485 (1996).

${ }^{14}$ S. J. Pearton and A. J. Tavendale, Journal of Physics C: Solid State Physics 17, 6701 (1984).

${ }^{15}$ K. Wünstel and P. Wagner, Solid State Communications 40, 797 (1981).

${ }^{16}$ T. Sadoh, K. Tsukamoto, A. Baba, D. Bai, A. Kenjo, T. Tsurushima, H. Mori, and H. Nakashima, Journal of Applied Physics 82, 3828 (1997).

${ }^{17}$ S. Leonard, V. P. Markevich, A. R. Peaker, B. Hamilton, and J. D. Murphy, Applied Physics Letters 107, 032103 (2015).

${ }^{18}$ E. B. Yakimov and A. L. Parakhonsky, Solid State Phenomena 57-58, 383 (1997).

${ }^{19}$ T. Takahashi and M. Suezawa, Physica B: Condensed Matter 273-274, 445 (1999).

${ }^{20}$ N. G. Szwacki, M. Sanati, and S. K. Estreicher, Physical Review B 78, 113202 (2008). 
${ }^{21}$ U. Wahl, J. G. Correia, E. Rita, J. P. Araújo, and J. C. Soares (The ISOLDE Collaboration), Physical Review B 72, 014115 (2005).

${ }^{22}$ D. J. Silva, U. Wahl, J. G. Correia, and J. P. Araújo, Journal of Applied Physics 114, 103503 (2013).

${ }^{23}$ D. Gilles, W. Schröter, and W. Bergholz, Physical Review B 41, 5770 (1990).

${ }^{24}$ G. Langouche, Hyperfine Interactions 72, 215 (1992).

${ }^{25}$ G. Weyer, S. Degroote, M. Fanciulli, V. N. Fedoseyev, G. Langouche, V. I. Mishin, A.-M. V. Bavel, A. Vantomme, and the ISOLDE Collaboration, in Defects in Semiconductors 19, Materials Science Forum, Vol. 258 (Trans Tech Publications, 1997) pp. 437-442.

${ }^{26}$ G. Weyer, A. Burchard, M. Fanciulli, V. N. Fedoseyev, H. P. Gunnlaugsson, V. I. Mishin, and R. Sielemann, Physica B: Condensed Matter 273, 363 (1999).

${ }^{27}$ Y. Yoshida, Y. Kobayashi, A. Yoshida, X. Diao, S. Ogawa, K. Hayakawa, K. Yukihira, F. Shimura, and F. Ambe, Hyperfine Interactions 141, 157 (2002).

${ }^{28}$ Y.Yoshida, S. Ogawa, and K. Arikawa, Physica B: Condensed Matter 340, 605 (2003), proceedings of the 22nd International Conference on Defects in Semiconductors.

${ }^{29}$ P. Karzel, A. Frey, S. Fritz, and G.Hahn, Journal of Applied Physics 113, 114903 (2013).

${ }^{30}$ A. Y. Liu, C. Sun, V. P. Markevich, A. R. Peaker, J. D. Murphy, and D. Macdonald, Journal of Applied Physics 120, 193103 (2016).

${ }^{31}$ G. Kresse and J. Hafner, Physical Review B. 47, 558 (1993).

${ }^{32}$ G. Kresse and J. Hafner, Physical Review B 49, 14251 (1994).

${ }^{33}$ G. Kresse and J. Furthmüller, Physical Review B 54, 11169 (1996).
${ }^{34}$ P. E. Blöchl, Physical Review B 50, 17953 (1994).

${ }^{35}$ J. P. Perdew, K. Burke, and M. Ernzerhof, Physical Review Letters 77, 3865 (1996)

${ }^{36}$ H. J. Monkhorst and J. D. Pack, Physical Review B 13, 5188 (1976).

${ }^{37}$ A. Resende, R. Jones, S. Öberg, and P. R. Briddon, Physical Review Letters 82, 2111 (1999).

${ }^{38} \mathrm{~J}$. Coutinho, V. J. B. Torres, R. Jones, and P. R. Briddon, Physical Review B 67, 035205 (2003).

${ }^{39}$ M. Shiraishi, J.-U. Sachse, H. Lemke, and J. Weber, Materials Science and Engineering: B 58, 130 (1999).

${ }^{40} \mathrm{C}$. Freysoldt, J. Neugebauer, and C. G. V. de Walle, Physical Review Letters 102 (2009), 10.1103/physrevlett.102.016402.

${ }^{41}$ J. Coutinho, V. P. Markevich, A. R. Peaker, B. Hamilton, S. B. Lastovskii, L. I. Murin, B. J. Svensson, M. J. Rayson, and P. R. Briddon, Physical Review B 86 (2012), 10.1103/physrevb.86.174101.

${ }^{42} \mathrm{G}$. Henkelman, B. P. Uberuaga, and H. Jónsson, The Journal of Chemical Physics 113, 9901 (2000).

${ }^{43}$ M. Sanati and S. K. Estreicher, Solid State Communications 128, 181 (2003).

${ }^{44}$ S. K. Estreicher, M. Sanati, D. West, and F. Ruymgaart, Physical Review B 70, 125209 (2004).

${ }^{45}$ B. Holm, K. B. Nielsen, and B. B. Nielsen, Physical Review Letters 66, 2360 (1991).

${ }^{46}$ N. Johnson, C. Herring, and C. V. de Walle, Physical Review Letters 74, 1889 (1995).

${ }^{47}$ K. B. Nielsen, B. B. Nielsen, J. Hansen, E. Andersen, and J. U. Andersen, Physical Review B 60, 1716 (1999).

${ }^{48}$ K. B. Nielsen, L. Dobaczewski, S. Søgård, and B. B. Nielsen, Physical Review B 65, 075205 (2002). 